\title{
In silico assessment of chronic toxicity of a combination drug namely 'Olmesartan medoxomil and Hydrochlorothiazide', marketed in Bangladesh
}

Matrika Saha Roy ${ }^{1 *}$, Rehnuma Tanjin ${ }^{1}$, Tanmoy Debnath, Bidduth Kumar Sarkar², Prema Modak, Milon Mondal ${ }^{3}$, Arghya Prosun Sarkar ${ }^{4}$, Md Ariful Islam $^{1}$ and Sukalyan Kumar Kundu ${ }^{1}$

\begin{abstract}
Background: Nowadays combination therapy has become more popular due to their additional effect, synergistic effect and antagonistic effect. Any of these can influence the treatment profile. Combination therapy is used to treat some chronic diseases like diabetes, hypertension, cancer etc. But recently India has banned some fixed dose drug combinations due to their increased chances of adverse drug effects and drug interactions. So it is the time to take a look on the present drug combinations available in Bangladesh. An in silico study may provide important information about their probable toxicities. Drugs available in the combination may deposit slowly in the body and may lead to toxicities. Here an antihypertensive drug combination 'Olmesartan medoxomil and Hydrochlorothiazide' had been studied.
\end{abstract}

Results: Olmesartan medoxomil and Hydrochlorothiazide have not been found to comply any similar protein to interact with each other, thus no possible chance of additional toxicity of the combination in case of long term use.

Conclusions: At first, using PubChem the ligand was searched for a canonical SMILE. By inputting the canonical SMILE in Protox, a basic information about toxicities was predicted. From Swiss Target Prediction, target proteins responsible for both efficacy and toxicity were identified. These protein structures were downloaded from Protein Data Bank and edited with Flare. Undesired amino acid, ligand-ligand complex, fatty acid, and water molecules were removed by PyMOL. Structurally modified proteins and ligands were inputted in Swiss PDB viewer for energy minimization. Energy minimization is a very important step because unfavorable bond length, bond strength and torsion angle between protein and ligand may interfere with docking procedure. Then docking between Olmesartan medoxomil (ligand) and the proteins responsible for efficacy and toxicity was performed by PyRx. Vina binding affinity provided the value of binding strength between the ligand and the proteins, which determines how strong the bond is. The more negative the vina binding affinity, the stronger the bond. Discovery studio software was used to visualize the docking complexes. Same steps were followed for Hydrochlorothiazide to identify proteins responsible for desired and undesired effects, but no toxic effect was found from protox.

Keywords: Combination therapy, Molecular docking, In silico method, Vina binding affinity

*Correspondence: matrikasaharoy.43@gmail.com

1 Department of Pharmacy, Jahangirnagar University, Savar, Dhaka 1342, Bangladesh

Full list of author information is available at the end of the article

\section{Background}

Combination therapy, also known as polytherapy indicates the use of two or more therapeutic agents for treating a disease condition with the moto to provide better 
treatment [1]. 'Polypharmacy' is a related term, that also means using multiple drugs whether for treating the same or separate medical conditions. The term 'Polymedicine' is also used for the similar meaning. It is believed that the combined drugs may show additional or synergistic effect to treat the disease better than any of those drugs could alone do. A combination therapy shows its effect by three mechanisms. Those are synergism, additive effect and antagonism. Among them synergism is the most desired effect, where the combined effect of the drugs is higher than their individual effects [2]. When the combined effect is the simple sum of the individual effects of those drugs, the condition is known as additive effect [2]. Finally, antagonism means the condition when the combined effect is less potent than the sum of individual potency of each drugs, that has been predicted. Combinations are now popular because of some reasons like with different mechanism of actions the drugs show the similar effect to treat the disease, drug resistance can be minimized and cost minimization. Another important fact is that when drugs are given in combination they are given in decreased dose, so toxicity of each drug decreases [2]. There are some disadvantages of combination therapy like in fixed dose combinations the dose is inflexible and their conflicting pharmacokinetics. Another one is that If two drugs interact with the same protein, by binding with which each of the drugs or their active metabolites show toxicity, then the combination may cause a great harm to the patients [2]. And if the combination is given for long term use, then these factors should be considered. India has banned 344 FDCs including the combination 'Olmesartan + Hydrochlorothiazide + Clorthalidone' because of toxicity observed, that is sudden reduction in blood pressure which leads to hypotension [3]. 'Olmesartan medoxomil + Hydrochlorothiazide' is a very popular combination that is available in Bangladesh. Not only in Bangladesh, this combination is highly used all over the world for treating hypertension. As 'Olmesar$\tan$ medoxomil+Hydrochlorothiazide' combination is close to 'Olmesartan + Hydrochlorothiazide + chlorthalidone' combination, it had been considered for predicting toxicity.

Olmesartan medoxomil is a nonpeptide angiotensin receptor blocker (ARB), which selectively and competitively inhibits type I angiotensin II receptor without affecting other receptors of the cardiovascular system. The type I angiotensin receptor is responsible for vasoconstriction and elevation of blood pressure. Olmesartan medoxomil is a prodrug that is rapidly converted to Olmesartan inside the body [4]. Olmesartan is a highly protein bound drug that has a low volume of distribution [4]. Hydrochlorothiazide belongs to a class of drugs known diuretics or water pills. Though the actual mechanism of action is not known yet, it is found to make more urine and inhibits the reabsorption of $\mathrm{Na}$ and Chloride in the distal tubules causing increased excretion of $\mathrm{Na}$ and water, Potassium and Hydrogen ions. So blood volume decreases and results in reduction of blood pressure [5].

Computer Aided Drug Design (CADD) is a computational technique that aims to make a link between information technology and chemistry [6]. New drug molecules can be designed, analyzed, developed by using this technology. CADD can be of two types [6]:

1. Structure based drug design (SBDD)

2. Ligand based drug design (LBDD)

Molecular docking is a tool in CADD that is used to predict the binding mode between a ligand and a target protein. The binding between a ligand and a protein is docked and is generally used in structure based drug design (SBDD) to predict both strength and type of signal produced $[7,8]$. Docking also provides information about binding affinity of the ligand to the protein, protein bound conformation and free energies of binding for small molecule ligands (drugs) to macromolecular targets (proteins) [8]. For virtual screening and understanding the function of the target, single docking experiments are useful. But in case of identifying new inhibitors for the purpose of drug development, a large number of compounds are docked and ranked [8].

\section{Methods}

Molecular docking is used to determine the binding characteristics between a ligand and a protein [8]. A large number of tools are available for this purpose but in this study only a few of those was used. Several websites and softwares are included in this process. These all are used step by step and the list is given bellow:

PubChem (https://pubchem.ncbi.nlm.nih.gov/), Protox (http://tox.charite.de/protox_II/), Swiss target prediction (http://www.swisstargetprediction.ch/), RCSB Protein Data Bank (https://www.rcsb.org/), Flare, PyMol, Swiss PDB, PyRx.

Here the combination 'Olmesartan medoxomil \& Hydrochlorothiazide' had been considered. Two drugs could not be taken at a time, so the same procedures were separately followed for both drugs one by one. First, the drug 'Olmesartan medoxomil' had been considered. From PubChem the structure of Olmesartan medoxomil had been searched and the 'Canonical SMILES' had been copied $[9,10]$. That is:

$$
\begin{aligned}
& C C C C 1=N C(=C(N 1 C C 2=C C=C(C=C 2) \\
& C 3=C C=C C=C 3 C 4=N N N=N 4) C(=O) \\
& O C C 5=C(O C(=O) O 5) C) C(C)(C) O
\end{aligned}
$$


The SMILES had been pasted in Protox [11]. From protox, informations about probable toxicities that might be showed by the drug had been obtained. It had been seen that the drug has active immunotoxicity (probability 0.96) [11]. After that Swiss Target Prediction had been used [12]. By pasting that canonical SMILES in the search option, the names of the proteins with which the drug might interact and the probabilities of those bindings had been observed [12]. A long list containing about 68 proteins had been obtained. Some of these proteins are responsible for the drug's desired effect. By binding with these proteins 'Olmesartan medoxomil' shows its hypertension lowering effect. But simultaneously the drug also binds with some other proteins in the system, that may not show any beneficial effect that enhances its' quality and acceptability as an antihypertensive drug. Among these proteins two proteins had been considered for docking purpose using Autodock Vina [13]. Those two proteins are:

I. Tyrosine-protein kinase JAK2

II. Angiotensin II receptor

From Protox it had been known that the drug might show immunotoxicity. After searching about the proteins with which the drug binds and might cause immunotoxicity had been identified then cleaned and saved properly. Those are:

1. Caspase- 8

2. COX-2

3. ADAM-17

4. Complement Factor-D

5. Endothelin receptor ET-B

6. Caspase-3

The 3D structures of these proteins had been downloaded from Protein Data Bank with resolution of 2-2.5 $\AA$ [14]. But those raw structures cannot be used for docking purpose. These structures not only consist of the desired protein portions but also some unnecessary spaces, amino acids, fatty acids, water molecules, other side molecules. So before using these for docking these unnecessary portions should be cleaned. This can be done by using PyMol software [15]. Sometimes while downloading any protein structure from the Protein Data Bank, the exact protein structure is not found. Rather the protein may be found in a complex form with other ligand that is not of our interest or protein-protein complex may also be found. In those cases, the software named Flare is used to edit the protein-ligand complex or protein-protein complex. The unnecessary ligand portion or protein chain is cut down from the desired protein portion. After doing all these processes a cleaned form of the desired protein is saved for further use. The cleaned protein structures had been opened in swiss PDB and energy minimization had been done so that the docking can be done properly [16]. Energy minimization is done to reduce the potential energy of the protein and ligand. The bond lengths and bond strengths inside the protein makes the protein and ligand unstable. So energy minimization is done prior to docking to get the optimal binding of the desired ligand with the desired protein [17]. As docking cannot be done in both cases when the protein's or ligand's size is either too big or too small. In maximum cases ligands are of small size, that's why energy minimization is not done in case of ligands. So in most of the cases energy minimization is done only for the proteins to make them stable [17]. These energy-minimized proteins had been saved for the next docking purpose. After preparing all target proteins and ligand, pyRx software had been used for the docking purpose [18]. Each protein had been docked with the ligand (Olmesartan medoxomil) and the result had been observed and interpreted properly (Figs. 1, 2, 3, 4, $5,6)$.

All the procedures that had been followed for Olmesartan medoxomil, once again those had been used step by step for Hydrochlorothiazide to determine the target proteins, by binding with which of them Hydrochlorothiazide shows intended effect and with which it shows toxicity. But no toxicity profile was found in case of Hydrochlorothiazide [11].

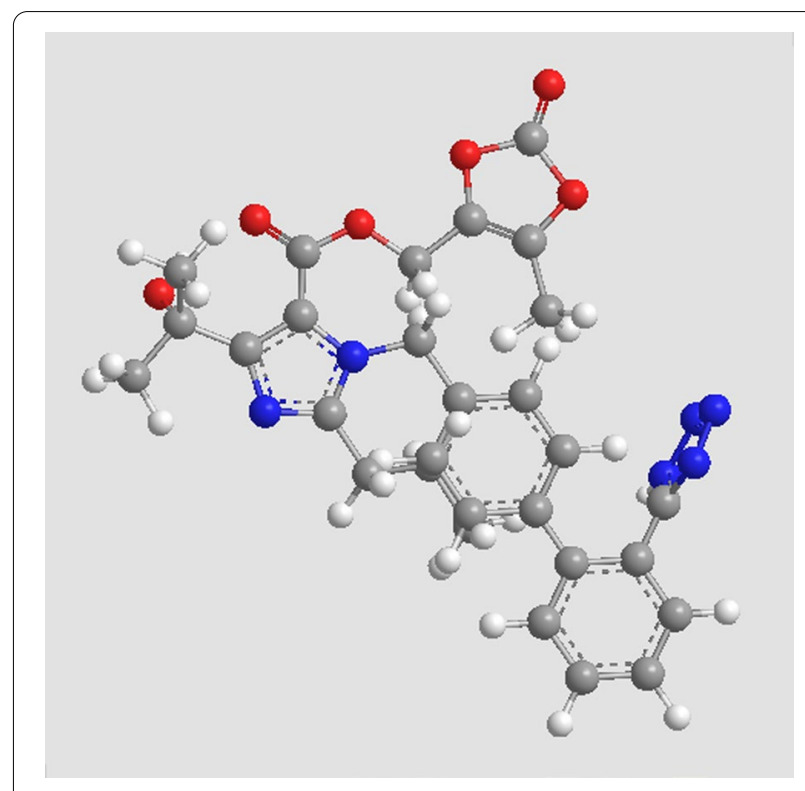

Fig. 1 Structure of Olmesartan medoxomil 


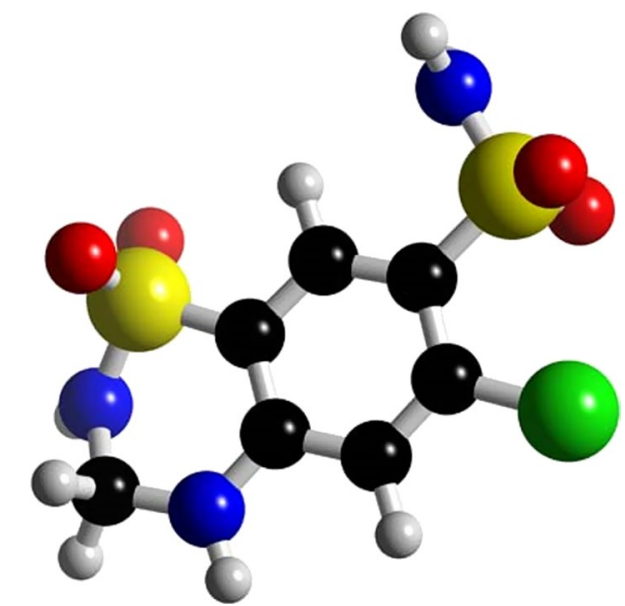

Fig. 2 Structure of Hydrochlorothiazide

\section{Result}

The goal of molecular docking is to understand and predict molecular recognition, finding likely binding modes both structurally and energetically, predicting binding affinity. For predicting toxicity of a combination drug, firstly each drug molecule needs to be considered separately and their basic characteristics should be known like volume, mass, $\mathrm{H}$ bond donor, $\mathrm{H}$ bond acceptor, $\mathrm{Log} \mathrm{P}$ (Table 1; Figs. 7, 8, 9, 10 and 11).

\section{Efficacy profiling of Olmesartan medoxomil}

Among the proteins that been identified for being responsible for showing intended effect of Olmesartan medoxomil after binding to it, two proteins had been docked with Olmesartan medoxomil for knowing the binding affinity. The software named autodock vina in PyRx had been used for this purpose.

Autodock vina in PyRx- Python prescription 0.8, is a virtual screening software for computational drug discovery that can be used to screen libraries of compounds against potential drug targeted [19]. Pyrx enables medicinal chemists to run virtual screening from any platform and helps users in every step of this process- from data preparation to job submission and analysis of the results.

\begin{tabular}{ll}
\hline Original author & Warren Lyford DeLano \\
\hline Developer & Schrödinger, Inc \\
Initial release & 2000; 20 years ago \\
Stable release & 2.3.2/17 May 2019; 11 months ago \\
Written in & C, C++, Python \\
Operating system & Cross-platform: macOS, Unix, Linux, Windows \\
Platform & IA-32, x86-64 \\
Available in & English \\
Type & Molecular modelling \\
License & Python \\
Website & pymol.org/ \\
\hline
\end{tabular}

\begin{tabular}{|c|c|c|c|c|}
\hline \multicolumn{5}{|c|}{ Toxicity Model Report } \\
\hline Classification & Target & Shorthand & Prediction & Probability \\
\hline Organ toxicity & Hepatotoxicity & dili & Inactive & 0.50 \\
\hline Toxicity end points & Carcinogenicity & carcino & Inactive & 0.59 \\
\hline Toxicity end points & Immunotoxicity & immuno & Active & 0.96 \\
\hline Toxicity end points & Mutagenicity & mutagen & Inactive & 0.58 \\
\hline Toxicity end points & Cytotoxicity & cyto & Inactive & 0.66 \\
\hline Tox21-Nuclear receptor signalling pathways & Aryl hydrocarbon Receptor (AhR) & nr_ahr & Inactive & 0.88 \\
\hline Tox21-Nuclear receptor signalling pathways & Androgen Receptor (AR) & nr_ar & Inactive & 0.96 \\
\hline Tox21-Nuclear receptor signalling pathways & Androgen Receptor Ligand Binding Domain (AR-LBD) & nr_ar_lbd & Inactive & 0.99 \\
\hline Tox21-Nuclear receptor signalling pathways & Aromatase & $\mathrm{nr}_{\text {_aromatase }}$ & Inactive & 0.96 \\
\hline Tox21-Nuclear receptor signalling pathways & Estrogen Receptor Alpha (ER) & nr_er & Inactive & 0.93 \\
\hline Tox21-Nuclear receptor signalling pathways & Estrogen Receptor Ligand Binding Domain (ER-LBD) & nr_er_lbd & Inactive & 0.97 \\
\hline Tox21-Nuclear receptor signalling pathways & $\begin{array}{l}\text { Peroxisome Proliferator Activated Receptor Gamma } \\
\text { (PPAR-Gamma) }\end{array}$ & nr_ppar_gamma & Inactive & 0.95 \\
\hline Tox21-Stress response pathways & $\begin{array}{l}\text { Nuclear factor (erythroid-derived 2)-like 2/antioxidant } \\
\text { responsive element (nrf2/ARE) }\end{array}$ & sr_are & Inactive & 0.94 \\
\hline Tox21-Stress response pathways & Heat shock factor response element (HSE) & sr_hse & Inactive & 0.94 \\
\hline Tox21-Stress response pathways & Mitochondrial Membrane Potential (MMP) & sr_mmp & Inactive & 0.82 \\
\hline Tox21-Stress response pathways & Phosphoprotein (Tumor Supressor) p53 & sr_p53 & Inactive & 0.93 \\
\hline Tox21-Stress response pathways & ATPase family AAA domain-containing protein 5 (ATAD5) & sr_atad5 & Inactive & 0.98 \\
\hline
\end{tabular}

Fig. 3 Basic idea about toxicity of Olmesartan medoxomil from Protox 


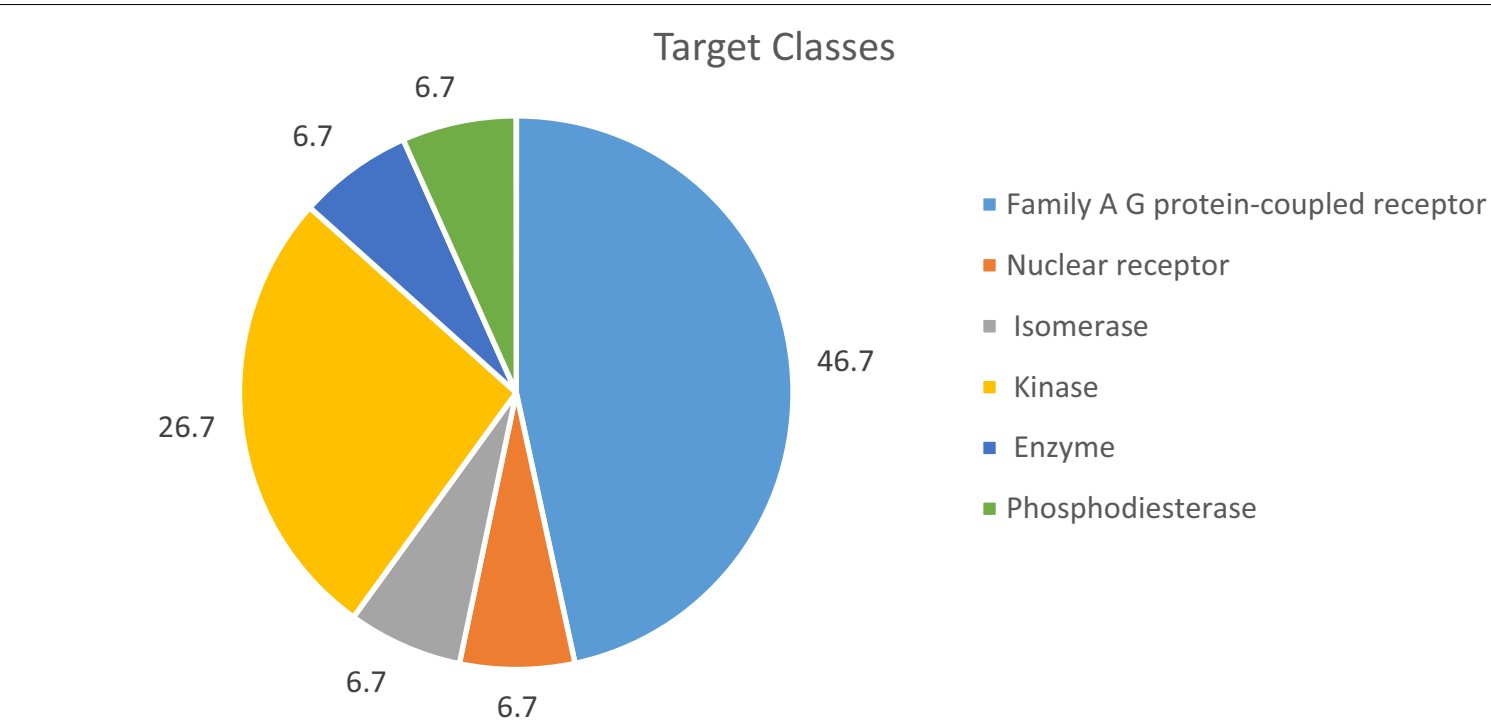

Fig. 4 A pie chart representing the target classes of enzymes with which Olmesartan medoxomil interact

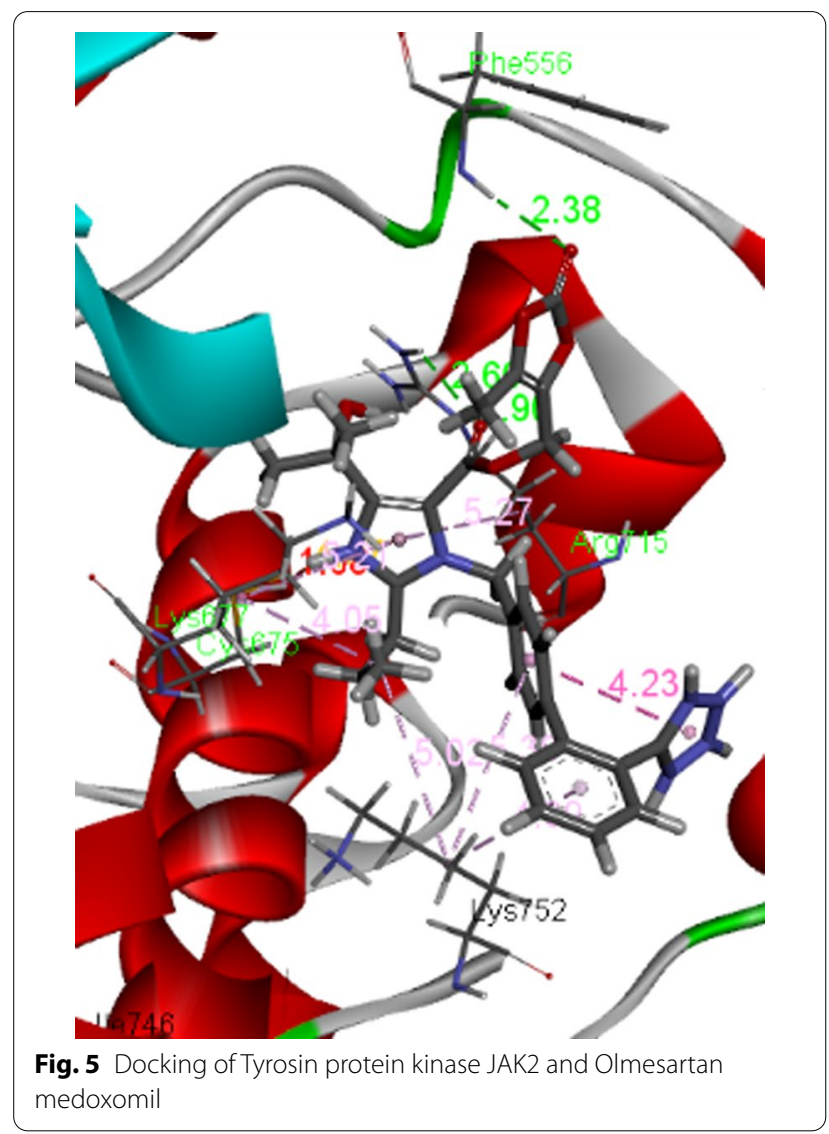

Tyrosine-protein kinase JAK2

See Table 2.

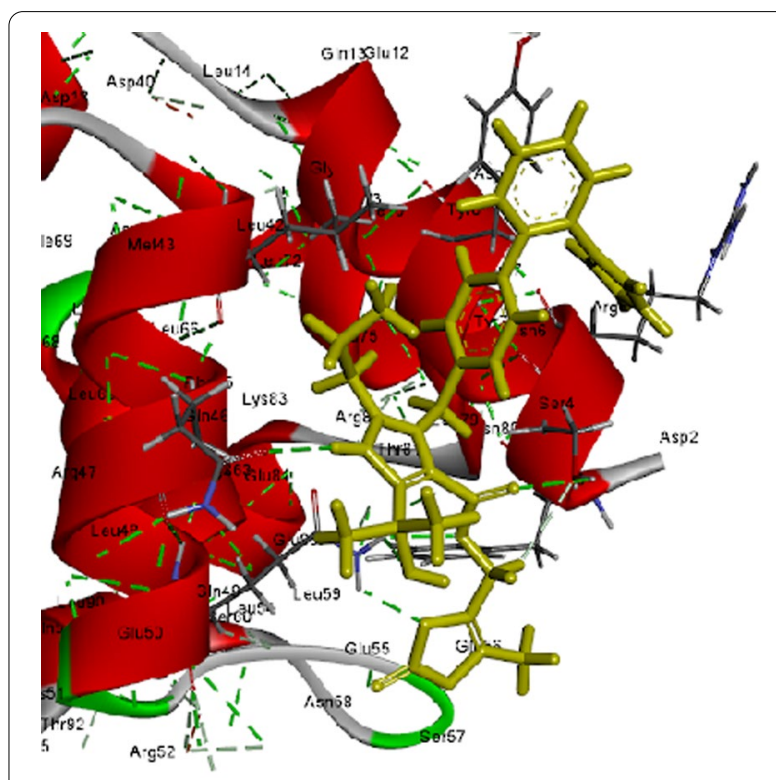

Fig. 6 Various bonds of Tyrosine-protein kinase JAK2 with different amino acids

\section{Toxicity profiling of Olmesartan medoxomil}

Caspase- 8 and COX-2 are two proteins, binding with which Olmesartan medoxomil shows immunotoxicity. Using Autodock Vina, docking of Olmesartan medoxomil (ligand) had been done with both Caspase- 8 and COX-2 (proteins). The amino acid sequence of Caspase- 8 and the specific amino acids with which Olmesartan medoxomil can bind, had been identified from PyMol (Tables 3, 4). 
Table 1 Molecular characteristics of Olmesartan medoxomil and Hydrochlorothiazide

\begin{tabular}{|c|c|c|c|c|c|}
\hline Compound & Volume $\left(\mathrm{cm}^{3}\right)$ & Mass (amu) & $\mathrm{H}$ bond donor & $\mathrm{H}$ bond acceptor & $\log P$ \\
\hline Olmesartan medoxomil & $403.5 \pm 7.0$ & 558.2 & 4 & 7 & 5.23 \\
\hline Hydrochlorothiazide & $175.8 \pm 3.0$ & 297.7 & 2 & 10 & -0.07 \\
\hline
\end{tabular}

Volume, mass, $\mathrm{H}$ bond donor, $\mathrm{H}$ bond acceptor, Log $\mathrm{P}$ are some basic characteristics of these drugs

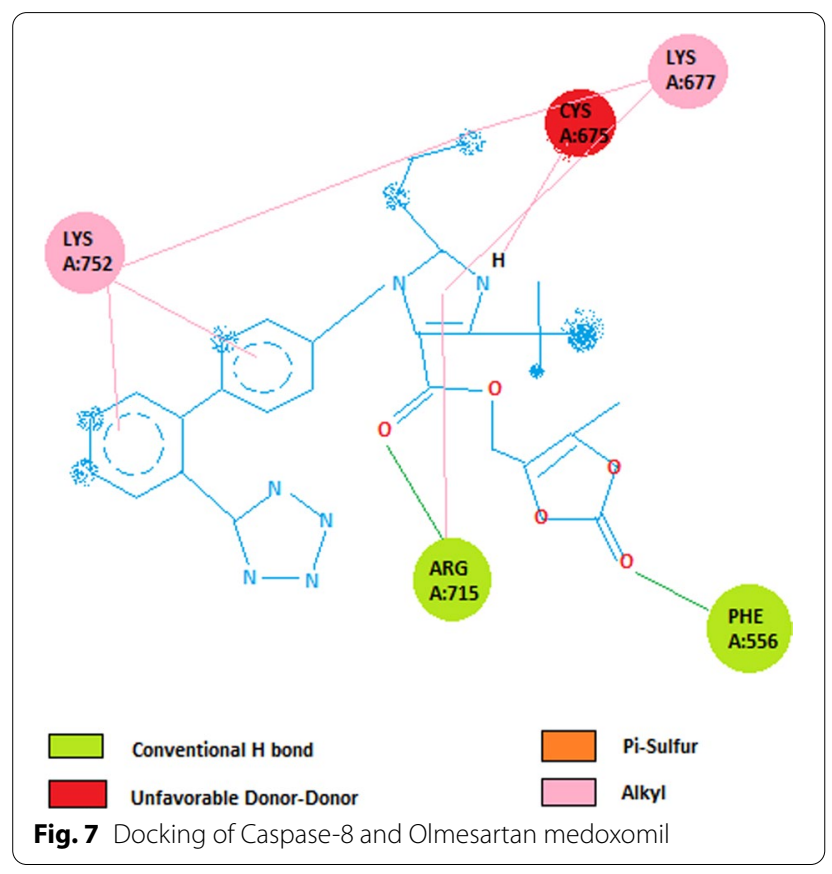

\section{Amino acid sequence of Caspase-8}

DFSRNLYDIGEQLDSEDLASLKFLSLDYIPQRKQEPIKDALMLFQRLQEKRMLEESNLSFLKELLFRINRLDLLITYLNTRKEEMERELQTPGRAQISAYRVMLYQISEEVSRSELRSFKFLLQEEISKCKLDDDMNLLDIFIEMKRVILGEGKLDILKRVCAQINKSLLKIINDYEE

(Bold marked amino acids represent that Olmesartan medoxomil interacts with these amino acids.) (Tables 5, 6).

\section{Amino acid sequence of COX-2}

GAPTPVNPCCYYPCQHQGICVRFGLDRYQCDCTRTGYSGPNCTIPGLWTWLRNSLRPSPSFTHFLLTHGRWFWEFVNATFIREMLMRLMRLVLTVRSNLIPSPPTYNSAHDYISWESFSNVSYYTRILPSVPKDCPTPMGTKGKKQLPDAQLLARRFLLRRKFIPDPQGTNLMFAFFAQHFTHQFFKTSGKMGPGFTKALGHGVDLGHIYGDNLERQYQLRLFKFGKLKYQVLDGEMYPPSVEEAPVLMHYPRGIPPQSQMAVGQEVFGLLPGLMLYATLWLREHNRVCDLLKAEHPTWGDEQLFQTTRLILIGETIKIVIEEYVQQLSGYFLQLKFD-
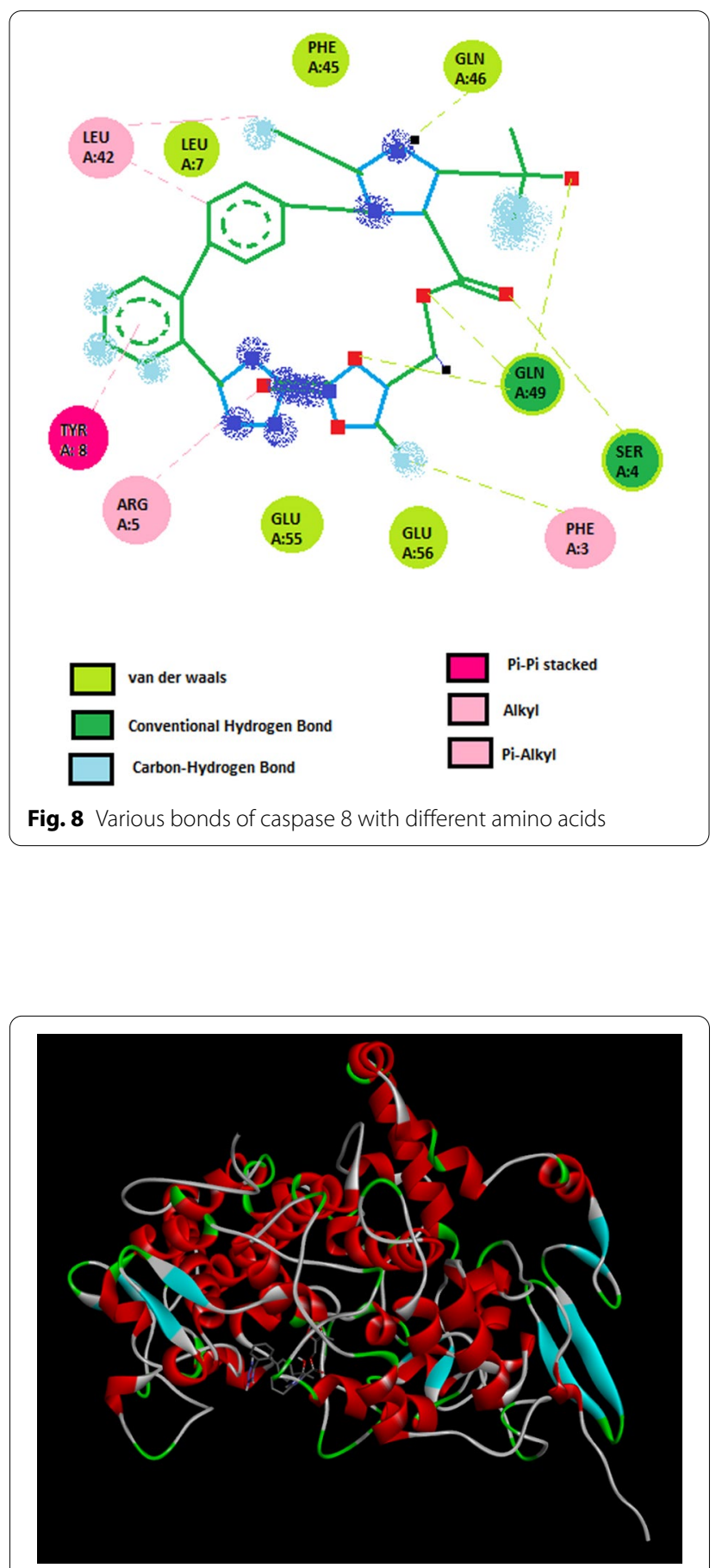

Fig. 9 Docking of COX-2 and Olmesartan medoxomil 


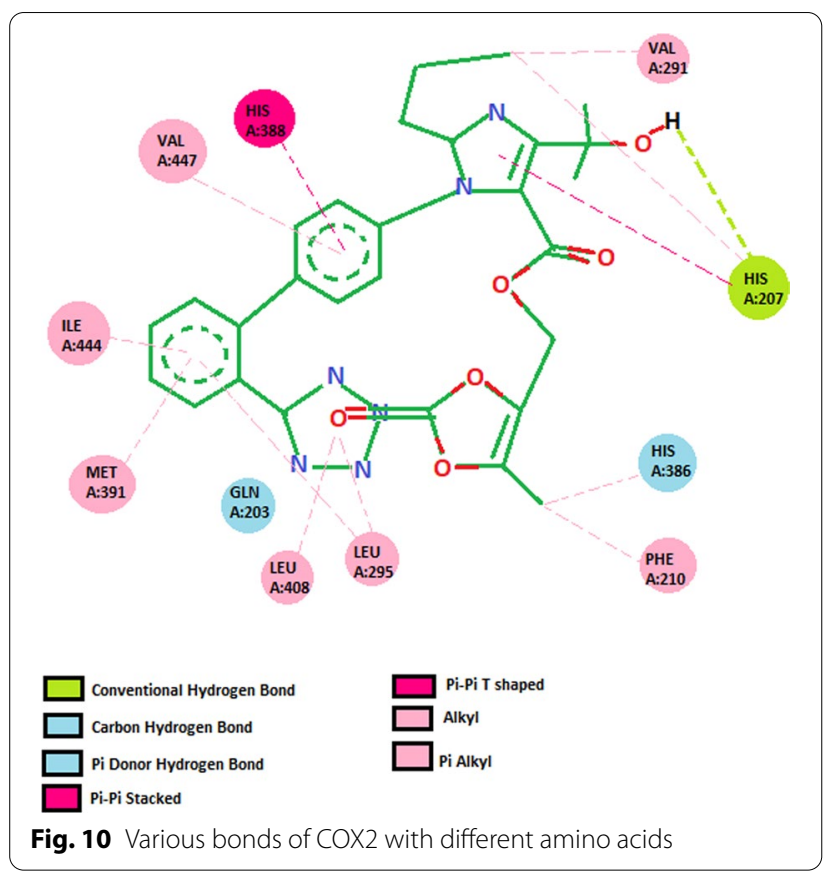

PELLFGVQFQYRNRIAMEFNHLYHWHPLMPDS FKVGSQEYSYEQFLFNTSMLVDYGVEALVDAFSRQIAGRIGGGRNMDHHILHVAVDVIRESREMRLQPFNEYRKRFGMKPYTSFQELVGEKEMAAELEELYGDIDALEFYPGLLLEKCHPNSIFGESMIEIGAPFSLKGLLGNPICSPEYWKPSTFGGEVGFNIVKTATLKKLVCLNTKTCPYVSFRVPD
(Bold marked amino acids represent that Olmesartan medoxomil interacts with these amino acids.)

\section{Comparison}

See Table 7.

\section{Discussion}

Docking, an in silico method, provides a basic idea about a drug's interaction to proteins. Caspase- 8 and COX-2 are two proteins, binding with which Olmesartan medoxomil shows immunotoxicity. Using Autodock Vina, docking of Olmesartan medoxomil (ligand) had been done with both Caspase- 8 and COX-2 (proteins). The amino acid sequence of Caspase- 8 and the specific amino acids with which Olmesartan medoxomil can bind, had been identified from PyMol. The energy which is released by bond formation and/or during interaction of the ligand and protein is termed in form of binding energy. For a favourable reaction, the free energy is negative. The binding of the ligand and protein becomes better if the binding energy is less in magnitude. In Autodock Vina, binding energy has been used to find out the ligand that shows stable complex interaction with protein (e.g. enzyme) [22]. And, the ligand-receptor complex will be more stable if it has more negative value or lower binding affinity. After docking of Olmesartan medoxomil with Caspase- 8 and COX-2, in between Caspase- 8 and COX-2, Olmesar$\tan$ medoxomil had been found to have lesser binding energy with COX-2. That means, Olmesartan medoxomil binds more strongly with COX-2 than Caspase-8, and

\begin{tabular}{|c|c|c|c|c|}
\hline Classification & Target & Shorthand & Prediction & Probability \\
\hline Organ toxicity & Hepatotoxicity & dili & Inactive & 0.92 \\
\hline Toxicity end points & Carcinogenicity & carcino & Inactive & 0.86 \\
\hline Toxicity end points & Immunotoxicity & immuno & Inactive & 0.94 \\
\hline Toxicity end points & Mutagenicity & mutagen & Inactive & 0.96 \\
\hline Toxicity end points & Cytotoxicity & cyto & Inactive & 0.69 \\
\hline Tox21-Nuclear receptor signalling pathways & Aryl hydrocarbon Receptor (AhR) & $\mathrm{nr} \_\mathrm{ahr}$ & Inactive & 0.99 \\
\hline Tox21-Nuclear receptor signalling pathways & Androgen Receptor (AR) & nr_ar & Inactive & 0.99 \\
\hline Tox21-Nuclear receptor signalling pathways & Androgen Receptor Ligand Binding Domain (AR-LBD) & nr_ar_lbd & Inactive & 1.0 \\
\hline Tox21-Nuclear receptor signalling pathways & Aromatase & nr_aromatase & Inactive & 0.99 \\
\hline Tox21-Nuclear receptor signalling pathways & Estrogen Receptor Alpha (ER) & nr_er & Inactive & 0.98 \\
\hline Tox21-Nuclear receptor signalling pathways & Estrogen Receptor Ligand Binding Domain (ER-LBD) & nr_er_lbd & Inactive & 0.99 \\
\hline Tox21-Nuclear receptor signalling pathways & $\begin{array}{l}\text { Peroxisome Proliferator Activated Receptor Gamma } \\
\text { (PPAR-Gamma) }\end{array}$ & nr_ppar_gamma & Inactive & 0.99 \\
\hline Tox21-Stress response pathways & $\begin{array}{l}\text { Nuclear factor (erythroid-derived 2)-like 2/antioxidant } \\
\text { responsive element (nrf2/ARE) }\end{array}$ & sr_are & Inactive & 0.99 \\
\hline Tox21-Stress response pathways & Heat shock factor response element (HSE) & sr_hse & Inactive & 0.99 \\
\hline Tox21-Stress response pathways & Mitochondrial Membrane Potential (MMP) & sr_mmp & Inactive & 0.99 \\
\hline Tox21-Stress response pathways & Phosphoprotein (Tumor Supressor) p53 & sr_p53 & Inactive & 0.99 \\
\hline Tox21-Stress response pathways & ATPase family AAA domain-containing protein 5 (ATAD5) & sr_atad5 & Inactive & 1.0 \\
\hline
\end{tabular}

Fig. 11 Toxicity prediction of Hydrochlorothiazide from Protox 
Table 2 2D and 3D structure of docked Olmesartan medoxomil and Tyrosine-protein kinase JAK2 receptor

\section{Docking of Tyrosine-protein kinase JAK2 receptor with Olmesartan medoxomil}

Vina Binding Affinity

$\mathrm{rmsd} / \mathrm{ub}$ and $\mathrm{rms} / / \mathrm{lb}$

2D structure

\section{$-8.5$}

Both are 0
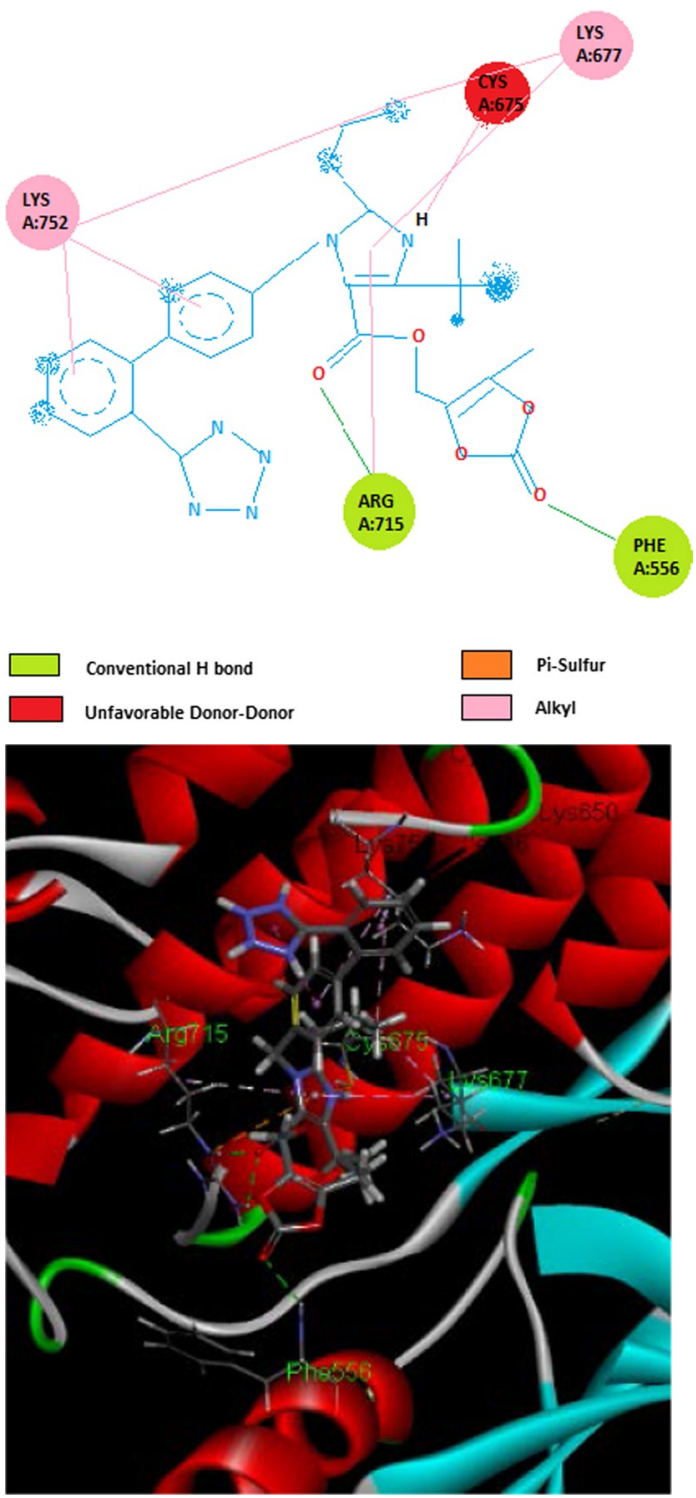

Vina binding affinity is -8.5

shows immunotoxicity. But Hydrochlorothiazide had not been found to have any toxicity from Protox, so no docking had been done with any protein. Again from Swiss Target Prediction, the name of proteins had been found with which Hydrochlorothiazide interacts. It had been seen that there is no common protein with which both Olmesartan medoxomil and Hydrochlorothiazide interact. The toxicity of the combination 'Olmesartan medoxomil \& Hydrochlorothiazide' is the combined toxic effect of Olmesartan medoxomil and Hydrochlorothiazide. As Hydrochlorothiazide had not been found to have any toxicity and common protein with which Olmesartan medoxomil interacts, the ultimate toxicity of the combination is the toxicity that is possessed by Olmesartan medoxomil. So this combination had been considered not to have any additional toxicity except that had been found in case of Olmesartan Medoxomil alone. 
Table 3 2D and 3D structure of docked Olmesartan medoxomil and Caspase-8

\section{Docking of Caspase-8 with Olmesartan medoxomil}

Vina binding affinity

$\mathrm{rmsd} / \mathrm{ub}$ and $\mathrm{rmsd} / \mathrm{lb}$

2D structure

3D structure

\section{$-7.1$ \\ 0.533}
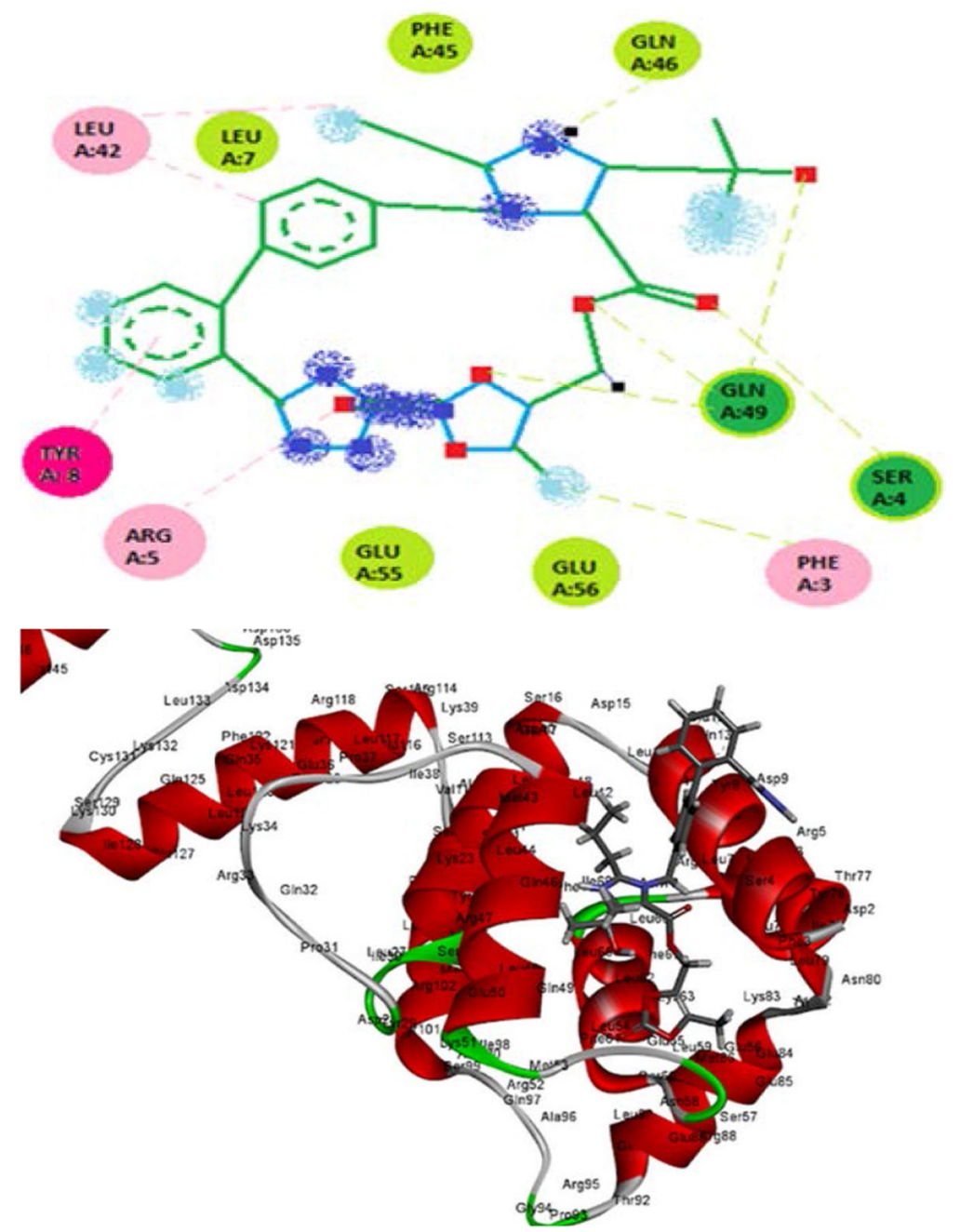

Vina binding affinity is -7.1 and RMSD value is $0.533[20,21]$

Table 4 Docking of Caspase-8 with Olmesartan medoxomil

\begin{tabular}{lllccc}
\hline SI No & Type of amino acid & Full name & Hydrophobicity & pKa $\begin{array}{l}\text { Avg. isotopic } \\
\text { displacement }\end{array}$ \\
\hline 1 & Serine & A:Ser26 & -0.8 & 48.166 \\
2 & Leucine & A:Leu27 & 3.8 & 51.52 \\
3 & Aspartic acid & A:Asp28 & -3.5 & 3.9 & 52.136 \\
4 & Tyrocine & A:Tyr29 & -1.3 & 10 & 63.487 \\
\hline
\end{tabular}

\section{Conclusion}

Proteins are responsible for any functions in the body, either beneficial or deleterious. Drugs also show their effects by binding with relevant receptor proteins. Activation of one protein may influence the action of another protein. That's why polypharmacy or 
Table 5 2D and 3D structure of docked Olmesartan medoxomil and COX-2

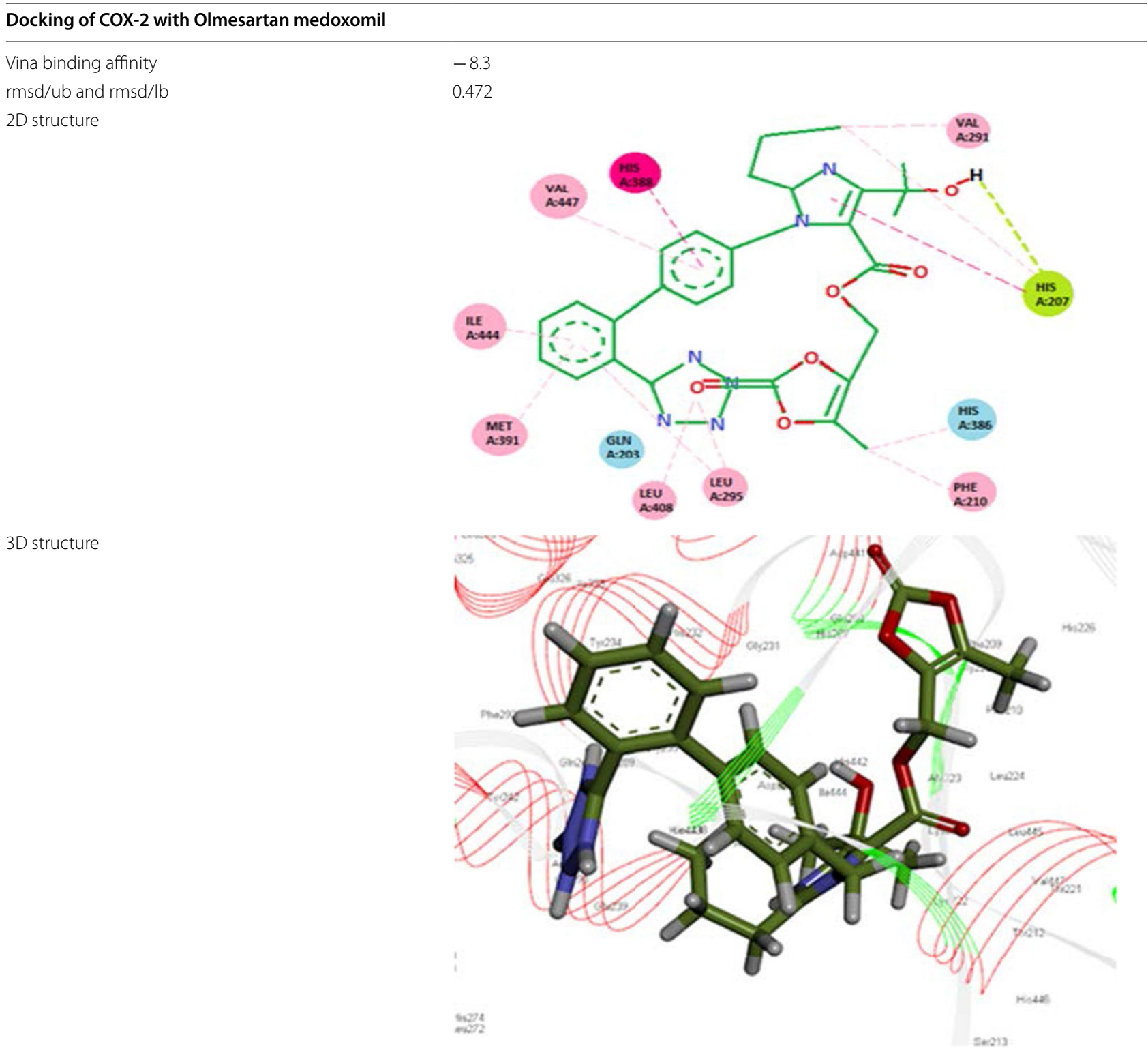

Vina binding affinity is -8.3 , and RMSD value is $0.472[20,21]$

combination therapy needs special consideration, as two or more drug works inside the body at the same time. A computer based system can help deciding either a drug combination is safe or not by providing data based knowledge about it. Here we studied about a well-used drug combination 'Olmesartan medoxomil and Hydrochlorothiazide'. It had been found that Olmesartan medoxomil binds with about 68 proteins, and Hydrochlorothiazide binds with about 13 proteins. But there is not a single protein in common with which both of these drugs are interacting. Again we had seen that
Olmesartan medoxomil might show immunotoxicity by interacting with 6 proteins, it had been possible to dock the drug with 2 of those proteins. But hydrochlorothiazide had been found to be a safe drug, as Protox did not show any toxicity prediction. So, it can be said that the combination 'Olmesartan medoxomil \& Hydrochlorothiazide' is safe. If chronically used Olmesartan medoxomil may show immunotoxicity, but hydrochlorothiazide is not anyhow responsible in promoting this toxicity. If Olmesartan medoxomil is given alone chronically as a drug, it may also show immunotoxicity in the 
Table 6 Docking of COX-2 and Olmesartan medoxomil

\begin{tabular}{|c|c|c|c|c|c|}
\hline SI No & Type of amino acid & Full name & Hydrophobicity & PKa & $\begin{array}{l}\text { Avg. isotopic } \\
\text { displacement }\end{array}$ \\
\hline 1 & Histidine & A:His43 & -3.2 & 6 & 94.488 \\
\hline 2 & Glutamine & $A: G \ln 44$ & -3.5 & & 86.792 \\
\hline 3 & Glycine & A:Gly51 & -0.4 & & 93.47 \\
\hline 4 & Leucine & A:Leu52 & 3.8 & & 95.75 \\
\hline 5 & Aspartic acid & A:Asp53 & -3.5 & 3.9 & 90.929 \\
\hline 6 & Threonine & A:Thr60 & -0.7 & & 88.487 \\
\hline 7 & Arginine & A:Arg61 & -4.5 & 12 & 87.718 \\
\hline 8 & Proline & A:Prp67 & -1.6 & & 89.393 \\
\hline 9 & Asparagine & A:Asn68 & -3.5 & & 98.224 \\
\hline
\end{tabular}

Table 7 Comparison between efficacy profiling and toxicity profiling of Olmesartan medoxomil

\begin{tabular}{|c|c|c|c|c|c|}
\hline \multicolumn{3}{|l|}{ Drug-1 } & \multicolumn{3}{|l|}{ Drug-2 } \\
\hline \multicolumn{3}{|l|}{ Olmesartan medoxomil } & \multicolumn{3}{|l|}{ Hydrochlorothiazide } \\
\hline Protein & Group & Vina binding affinity & Protein & Group & Free energy \\
\hline $\begin{array}{l}\text { Tyrosine protein kinase JAK2 } \\
\text { receptor }\end{array}$ & Efficacy & -8.5 & Carbonic amhydrases & Efficacy & $\mathrm{N} / \mathrm{A}$ \\
\hline Caspase-8 & Toxicity & -7.1 & $\begin{array}{l}\text { Glutamate receptor ionotropic, } \\
\text { AMPA 1, AMPA } 2\end{array}$ & Efficacy & N/A \\
\hline $\operatorname{cox}-2$ & Toxicity & -8.3 & & & \\
\hline
\end{tabular}

patients. But the combination 'Olmesartan medoxomil \& Hydrochlorothiazide' shows better effect in reducing blood pressure than only 'Olmesartan medoxomil'. So using the combination will be preferable for hypertension patients, as the combination had not been found to produce any additional toxicity. Rather, using this combination increases the antihypertensive effect by working synergistically.

\section{Abbreviations}

FDC: Fixed dose combination; ARB: Angiotensin receptor blocker; CADD: Computer aided drug design; SBDD: Structure based drug design; LBDD: Ligand based drug design; PDB: Protein Data Bank; RMSD: Root mean square deviation; COX: Cyclooxygenase.

\section{Acknowledgements}

My cordial thanks to Dr. Sukalyan Kumar Kundu, professor of Jahangirnagar University for his help and support throughout my research project.

\section{Authors' contributions}

The idea of performing this research and designing of methodology came from MSR and SKK. All authors contributed equally to perform the analysis and to collect experimental data under the supervision of SKK. Data analysis was conducted by MSR and RT. The draft manuscript was prepared by MSR with the assistance of SKK, BKS and RT. SKK critically reviewed the manuscript. All authors read and approved the final manuscript.

\section{Funding}

Authors did not have any financial assistance from any source, and it was a selfffunded research work.
Availability of data and materials

The datasets used and/or analyzed during the study are available from the corresponding author on request.

\section{Declarations}

Ethics approval and consent to participate

Not applicable.

\section{Consent for publication}

Not applicable.

\section{Competing interests}

The authors declare that they have no competing interests to conduct the study.

\section{Author details}

${ }^{1}$ Department of Pharmacy, Jahangirnagar University, Savar, Dhaka 1342, Bangladesh. ${ }^{2}$ Department of Pharmacy, Comilla University, Cumilla 3506 Bangladesh. ${ }^{3}$ Department of Pharmacy, Bangabandhu Sheikh Mujibur Rahman Science and Technology University, Gopalganj, Bangladesh. ${ }^{4}$ Department of Pharmacy, Islamic University, Kushtia, Bangladesh.

Received: 16 April 2021 Accepted: 11 December 2021

Published online: 20 December 2021

\footnotetext{
References

1. Shenfield GM (1982) Fixed combination drug therapy. Drugs 23(6):462480. https://doi.org/10.2165/00003495-198223060-00003

2. Bukowska B, Gajek A, Marczak A (2015) Two drugs are better than one. A short history of combined therapy of ovarian cancer. Contemp Oncol 19(5):350-353. https://doi.org/10.5114/wo.2014.43975
} 
3. Miranda M, Dubey A, Ravi GS, Charyulu RN (2019) Fixed-dose combinations banned in India: is it the right decision? An eye-opening review. Expert Opin Drug Saf 18(10):977-985. https://doi.org/10.1080/14740338. 2019.1651292

4. Brunner HR (2002) The new oral angiotensin II antagonist olmesartan medoxomil: a concise overview. J Hum Hypertens 16(Suppl 2):S13-S16. https://doi.org/10.1038/sj.jhh.1001391

5. Vongpatanasin W (2015) Hydrochlorothiazide is not the most useful nor versatile thiazide diuretic. Curr Opin Cardiol 30(4):361-365. https://doi. org/10.1097/HCO.00000000000000178

6. Yu W, Mackerell AD Jr (2017) Computer-aided drug design methods. Methods Mol Biol 1520:85-106. https://doi.org/10.1007/ 978-1-4939-6634-9 5

7. Blundell TL (1996) Structure-based drug design. Nature 384(6604 Suppl):23-26. https://doi.org/10.1038/384023a0

8. Ferreira LG, Dos Santos RN, Oliva G, Andricopulo AD (2015) Molecular docking and structure-based drug design strategies. Molecules 20(7):13384-13421. https://doi.org/10.3390/molecules200713384

9. Kim S, Chen J, Cheng T, Gindulyte A, He J, He S, Li Q, Shoemaker BA, Thiessen PA, Yu B, Zaslavsky L, Zhang J, Bolton EE (2019) PubChem 2019 update: improved access to chemical data. Nucleic Acids Res 47(D1):D1102-D1109. https://doi.org/10.1093/nar/gky1033

10. Kim S, Thiessen PA, Bolton EE, Chen J, Fu G, Gindulyte A, Han L, He J, He S, Shoemaker BA, Wang J, Yu B, Zhang J, Bryant SH (2016) PubChem substance and compound databases. Nucleic Acids Res 44(D1):D1202D1213. https://doi.org/10.1093/nar/gkv951

11. Banerjee P, Eckert AO, Schrey AK, Preissner R (2018) ProTox-ll: a webserver for the prediction of toxicity of chemicals. Nucleic Acids Res 46(W1):W257-W263. https://doi.org/10.1093/nar/gky318

12. Gfeller D, Grosdidier A, Wirth M, Daina A, Michielin O, Zoete V (2014) SwissTargetPrediction: a web server for target prediction of bioactive small molecules. Nucleic Acids Res 42:W32-W38. https://doi.org/10.1093/nar/ gku293

13. Seeliger D, de Groot BL (2010) Ligand docking and binding site analysis with PyMOL and Autodock/Vina. J Comput Aided Mol Des 24(5):417-422. https://doi.org/10.1007/s10822-010-9352-6

14. Berman HM, Westbrook J, Feng Z, Gilliland G, Bhat TN, Weissig H, Shindyalov IN, Bourne PE (2000) The Protein Data Bank. Nucleic Acids Res 28(1):235-242. https://doi.org/10.1093/nar/28.1.235

15. Lill MA, Danielson ML (2011) Computer-aided drug design platform using PyMOL. J Comput Aided Mol Des 25(1):13-19. https://doi.org/10.1007/ s10822-010-9395-8

16. Hussain MR, Shaik NA, Al-Aama JY, Asfour HZ, Khan FS, Masoodi TA, Khan MA, Shaik NS (2012) In silico analysis of Single Nucleotide Polymorphisms (SNPs) in human BRAF gene. Gene 508(2):188-196. https://doi.org/10. 1016/j.gene.2012.07.014

17. Levitt M (1983) Protein folding by restrained energy minimization and molecular dynamics. J Mol Biol 170(3):723-764. https://doi.org/10.1016/ s0022-2836(83)80129-6

18. Mukund V, Saddala MS, Farran B, Mannavarapu M, Alam A, Nagaraju GP (2019) Molecular docking studies of angiogenesis target protein HIF-1a and genistein in breast cancer. Gene 701:169-172. https://doi.org/10. 1016/j.gene.2019.03.062

19. Dallakyan S, Olson AJ (2015) Small-molecule library screening by docking with PyRx. Methods Mol Biol 1263:243-250. https://doi.org/10.1007/9781-4939-2269-7_19

20. Kufareva I, Abagyan R (2012) Methods of protein structure comparison. Methods Mol Biol 857:231-257. https://doi.org/10.1007/978-1-61779588-6_10

21. Reva BA, Finkelstein AV, Skolnick J (1998) What is the probability of a chance prediction of a protein structure with an rmsd of 6 A? Fold Des 3(2):141-147. https://doi.org/10.1016/s1359-0278(98)00019-4

22. Chen D, Oezguen N, Urvil P, Ferguson C, Dann SM, Savidge TC (2016) Regulation of protein-ligand binding affinity by hydrogen bond pairing Sci Adv 2(3):e1501240. https://doi.org/10.1126/sciadv.1501240

\section{Publisher's Note}

Springer Nature remains neutral with regard to jurisdictional claims in published maps and institutional affiliations.

\section{Submit your manuscript to a SpringerOpen ${ }^{\circ}$ journal and benefit from:}

- Convenient online submission

- Rigorous peer review

- Open access: articles freely available online

- High visibility within the field

- Retaining the copyright to your article

Submit your next manuscript at $\boldsymbol{\nabla}$ springeropen.com 